\title{
Guidelines for osteoporosis in coeliac disease and inflammatory bowel disease
}

\author{
E M Scott, I Gaywood, B B Scott for the British Society of Gastroenterology
}

The review upon which these guidelines are based was originally published in Eur 7 Gastroenterol Hepatol 1998;10:689-98.
Department of

Endocrinology, St

James's University

Hospital,

Leeds LS9 7TF, UK

E M Scott

Department of

Gastroenterology,

County Hospital,

Greetwell Road,

Lincoln LN2 5QY, UK

B B Scott

Department of

Rheumatology, County

Hospital

I Gaywood

Correspondence to: Dr B B Scott.

\subsection{The problem}

Osteoporotic fractures are a major public health problem. It has been estimated that in the USA the remaining lifetime fracture risk at the age of 50 years is $40 \%$ for white women and $13 \%$ for white men, ${ }^{1}$ the major fracture sites being spine, forearm and hip. This results in considerable morbidity and mortality and rising costs, including acute hospital care and long term care in the home or nursing home. The estimated total annual cost of osteoporotic fractures in England and Wales is $£ 742$ million (\$464 million). ${ }^{2}$ These costs are likely to increase as the population ages.

\subsection{Screening}

2.1 BONE MINERAL DENSITY

Osteoporosis can be reliably detected by measurement of bone mineral density (BMD), which can be expressed as the number of SDs above or below either the mean BMD for young adults ( $\mathrm{T}$ score) or the mean BMD for age matched controls ( $\mathrm{Z}$ score). A BMD more than $2.5 \mathrm{SD}$ below the mean for a young adult is generally taken to indicate osteoporosis. ${ }^{3}$ Stratification for fracture risk is possible using BMD. The risk increases roughly twofold for each SD decline in BMD below the population mean. ${ }^{4}$ This compares with a 1.5 -fold increase in the risk of death from coronary artery disease with each SD increase in cholesterol concentrations or diastolic pressure.

\subsection{RISK FACTORS FOR FRACTURE}

It is important to recognise that osteoporosis is but one of a number of factors predisposing to fracture, just as a raised cholesterol and diastolic pressure are each just one of many factors predisposing to coronary artery disease. Awareness of surroundings, mobility, and eyesight collectively contribute to a tendency to fall and all are likely to be important. ${ }^{6}$ Furthermore, bone strength is largely related to trabecular structure, certainly in the proximal femur, whereas BMD is a composite measurement of both cortical and trabecular bone. ${ }^{7}$ Although the population can be stratified for fracture risk using $\mathrm{BMD}$ measurements, its poor sensitivity for predicting actual fracture makes it unsuitable for screening the whole population or even all post-menopausal women - the difficulties and costs are great and it would have only a small contribution to fracture prevention in the community as a whole. $^{38-10}$ The alternative is to target certain high risk groups for screening or treatment, or both.
2.3 METHODS OF MEASURING BONE MINERAL DENSITY

There are several methods available for measuring BMD. ${ }^{11}$ Dual energy $x$ ray absorptiometry (DEXA) is currently most favoured, but is relatively costly and is not widely available; roughly 100 instruments have been installed in the UK. Broadband ultrasound attenuation of the heel gives an index of BMD which discriminates patients with and without osteoporosis almost as well as actual measurements of bone density ${ }^{12}$ and is predictive of hip fracture. ${ }^{6}$ It may also reflect bone architecture which contributes to overall bone strength, ${ }^{13}$ is relatively cheap and the machine is portable. However, its usefulness in monitoring response to treatment has not been validated.

2.4 RISK FACTORS FOR OSTEOPOROSIS

There are many risk factors for osteoporosis including endocrine, metabolic and nutritional disorders, and drugs. The value of screening groups in which the incidence of fracture is increased is likely to be greater, and targeting such patients should at least be considered even in the absence of cost-benefit studies. Furthermore, many of these who are at increased risk are already under medical supervision and the uptake of screening and treatment is likely to be high. Doctors responsible for the management of such patients should seriously consider their role in detecting and treating osteoporosis.

\subsection{ROLE OF GASTROENTEROLOGISTS}

Gastroenterologists care for a large proportion of patients at increased risk of osteoporosis. The two main groups are those with coeliac disease and inflammatory bowel disease (IBD), especially those on steroids. Alcoholism and chronic liver disease are also important but are not considered in these guidelines.

\subsection{Coeliac disease}

3.1 STUDIES OF BONE MINERAL DENSITY IN COELIAC DISEASE

The evidence for reduced BMD in coeliac disease is good. ${ }^{14-22}$ One study ${ }^{19}$ showed that $47 \%$ of women and $50 \%$ of men on a gluten-free diet had osteoporosis defined as BMD more than 2 SD below mean peak bone mass measured by DEXA. The BMD was positively related to calcium intake, body mass index

Abbreviations used in these guidelines: BMD, bone mineral density; IBD, inflammatory bowel disease; DEXA, dual energy $x$ ray absorptiometry; BMI, body mass index; CT, computed tomography; HRT, hormone replacement therapy; IL, interleukin; APD, (3-amino-1-hydroxypropylidene)-1,1-bisphosphonate. 
(BMI) and menopausal age. Other studies have shown significant improvement one year after starting a gluten-free diet ${ }^{23}$ normal BMD in patients who had been on a gluten-free diet since childhood, ${ }^{15}$ and improved bone mineralisation on a gluten-free diet in childhood and adolescence. ${ }^{24}$ The incidence of fractures in coeliac disease is not known but there is no reason to suppose that the reduction in BMD is less predictive of fracture risk than in the general population. The abstract of one study ${ }^{25}$ reported a significantly higher proportion of patients with a history of fracture than controls (21 $v 3 \%$ ). The mean age was 52 years and there was no relation between fracture and BMD.

\subsection{MECHANISM UNDERLYING OSTEOPOROSIS IN} COELIAC DISEASE

The mechanism underlying osteoporosis in coeliac disease is likely to be related to calcium malabsorption leading to increased parathormone secretion which, in turn, increases bone turnover and cortical bone loss. ${ }^{26}$ Vitamin D malabsorption is probably of less importance. Of course, it must be remembered that osteomalacia may co-exist, especially before treatment, and will require treatment with vitamin D. Furthermore, osteomalacia may affect the result of DEXA. In some men there may be loss of gonadal function ${ }^{27}$ which may, as in women, contribute to osteoporosis. ${ }^{28}$ Unfortunately, serum testosterone concentrations are unlikely to be helpful in planning testosterone replacement therapy because the concentrations tend to be high, especially before treatment, owing to androgen resistance. ${ }^{27}$ There seems to be impairment of peripheral reduction of testosterone to the active dihydrotestosterone. ${ }^{27}$

\subsection{Inflammatory bowel disease}

4.1 STUDIES OF BONE MINERAL DENSITY IN INFLAMMATORY BOWEL DISEASE

The results of studies of osteoporosis in inflammatory bowel disease (IBD) are less consistent than in coeliac disease which is not surprising given the great variation in site, extent and severity of disease between patients, variation of all these with time, and associated drug treatment, especially steroids.

Compston and colleagues ${ }^{29}$ studied the forearm with single photon absorptiometry and the lumbar spine with quantitative computed tomography (CT) scanning in 17 patients with ulcerative colitis, 51 with Crohn's disease (46 with small bowel involvement and 38 with resections) and four with indeterminate IBD. They found osteoporosis (defined as a BMD more than $2 \mathrm{SD}$ below the age matched control mean) in $14 \%$ of patients with ulcerative colitis and $41 \%$ of those with Crohn's disease. All except eight in each group had taken steroids. The BMD correlated negatively with lifetime steroid use and positively with BMI. A higher percentage of men than women had osteoporosis, which might reflect the use of hormone replacement therapy (HRT) in women whereas the men were unlikely to have been offered testosterone. Motley and colleagues ${ }^{30}$ studied the lumbar spine using CT scanning repeated at one year in 54 patients with IBD and found a rapid rate of trabecular bone loss in $20 \%$. No significant correlation with steroid use was found. There was a negative correlation with BMI. Clements and colleagues ${ }^{31}$ studied 50 patients with IBD at intervals over a mean of eight years using single photon absorptiometry and found increased rates of cortical bone loss in some. Silvennoinen and colleagues, ${ }^{32}$ using DEXA of the lumbar spine and femoral neck, studied 67 patients with ulcerative colitis, 78 with Crohn's disease, and seven with indeterminate IBD. Of these, $30 \%$ had a $\mathrm{Z}$ score of -1 or below compared with $16 \%$ of controls. The BMD correlated negatively (slightly) with lifetime steroid use. There was no significant reduction in BMD in those who had never received steroids. A study published in abstract form $^{33}$ of forearm CT scanning in 61 patients with Crohn's disease, 22 with ulcerative colitis and seven with indeterminate IBD showed that $19 \%$ had trabecular density more than 2 SD below the control mean. In another abstract ${ }^{34}$ of a study of 38 patients with ulcerative colitis, DEXA showed no significant difference in BMD between patients and controls, but on repeat testing at one year there was a significant fall in BMD in the group of six men who had received steroids. A DEXA study from Norway $^{35}$ confirmed reduced BMD in 60 patients with Crohn's disease but not in 60 with ulcerative colitis, whereas a DEXA study from England, ${ }^{36}$ which found osteoporosis in $27 \%$ of 79 patients with IBD (44 with Crohn's disease and 35 with ulcerative colitis) stated that there was no significant difference between Crohn's disease and ulcerative colitis.

4.2 FACTORS CAUSING OSTEOPOROSIS IN INFLAMMATORY BOWEL DISEASE

Only one ${ }^{36}$ of these studies used the generally accepted criterion for osteoporosis (i.e., BMD $>2.5$ SD below mean for young adults). Nevertheless, taken together they suggest that osteoporosis is common in Crohn's disease and less so in ulcerative colitis, and that there is a positive correlation between BMD and BMI, and a negative correlation with steroid use. Furthermore, BMD may be reduced relatively more in men than in women.

In men testosterone deficiency may contribute to osteoporosis. Testicular function may be impaired in Crohn's diseas $\mathrm{e}^{37}$ as well as in those on steroids ${ }^{38} 39$ and although it is not known whether this is related to testosterone deficiency, depressed blood testosterone concentrations were found in three of 19 patients with Crohn's disease. ${ }^{27}$

\subsection{Steroid use}

5.1 EFFECT OF STEROIDS ON BONE

Steroids have a number of adverse effects on bone. They suppress circulating oestrogen, thus reducing its role in inhibiting the cytokine interleukin (IL) 6 , which is a stimulator of osteoclastic activity. ${ }^{40}$ In men steroids reduce blood testosterone concentrations ${ }^{38}{ }^{39}$ resulting in a similar effect on bone. ${ }^{39}$ Steroids also inhibit osteoblast maturation, synthetic ability, 
Box 1-Summary strategy for prevention and treatment of osteoporosis in coeliac disease

GENERAL ADVICE

- Strict gluten-free diet $\star \star$

- Adequate dietary calcium; add calcium tablets if necessary to ensure daily intake of $1500 \mathrm{mg} \star \star \star$

- Exercise $\star \star \star$

- No smoking $\star \star$

- No alcohol excess $\star \star$

- Seek and treat vitamin D deficiency

- Measure BMD at diagnosis; if low reinforce above advice

POSTMENOPAUSAL WOMEN

- Measure BMD at menopause or when first seen

- If osteoporotict offer:

- HRT, preferably by skin patch, or $\star \star \star$

- Bisphosphonate orally, or $\star \star \star$

- Calcitonin $\star \star \star$

MEN >55 YEARS

- Measure BMD

- If osteoporotic $\nmid$ offer bisphosphonate or calcitonin $\star \star$

ALL WITH FRAGILITY FRACTURE

- Measure BMD

- If osteoporotict offer HRT (if post menopausal), bisphosphonate or calcitonin $\star \star$

- If already on HRT consider adding bisphosphonate or calcitonin *

DURATION OF DRUG TREATMENT

- For bisphosphonate and calcitonin measure BMD yearly

- If BMD falls $>4 \%$ per year in two successive years change to other drug

- If no fall continue drug for at least three years - possibly long term $\star \star \star$

- Restart drug if, on stopping, yearly BMD falls $>4 \%$

- For HRT check BMD after 10 years and continue HRT if osteoporosis persists *

†Osteoporosis defined as BMD $>2.5 \mathrm{SD}$ below mean for young adult. ${ }^{\star \star \star},{ }^{\star \star}$ and * indicate the level of evidence for the recommendation (see text).

and calcium absorption and increase urinary loss, thus causing secondary hyperparathyroidism which increases bone remodelling. However, in Crohn's disease the relation between steroids and reduced BMD could also be partly explained by the associated increased activity of the disease necessitating the steroids. Preliminary data ${ }^{41}$ suggest that circulating IL-6 is both increased in active disease and associated with low BMD.

\subsection{DOSE RELATED EFFECT}

A review of osteoporosis associated with steroid use ${ }^{42}$ reports that although the association is real, the true incidence of osteoporosis in steroid treated patients is unknown. Estimates of the fraction of patients on long term steroids who will experience fractures vary from one half ${ }^{42}$ to one quarter. ${ }^{43}$ Nevertheless, certain conclusions seem valid. Significant bone loss is caused by doses of prednisolone of $7.5 \mathrm{mg}$ daily or greater in most patients. Bone loss is more rapid in the early weeks of treatment. The usual risk factors for osteoporosis (age, race, sex, menopausal state, and parity) do not apply to the same extent to steroid induced bone loss. In fact, one study suggested that young people on steroids lose bone more rapidly than older patients, and another showed that men and women and blacks and whites are equally susceptible.

\subsection{Strategies for preventing and treating} osteoporosis

6.1 GENERAL MEASURES

The risk should be explained and general advice given about exercise (particularly weight bearing), smoking, alcohol excess, and adequate dietary calcium. A total daily calcium intake of $1500 \mathrm{mg}$ should be ensured - a pint of skimmed milk provides $700 \mathrm{mg}$. If dietary calcium is inadequate $500-1000 \mathrm{mg}$ supplemental calcium should be given (e.g., one or two Calcichew (Shire, UK) tablets daily). In coeliac disease the importance of adhering strictly to a gluten-free diet should be stressed. Vitamin D deficiency should be sought and treated if found. Clinicians usually rely on serum calcium, phosphate and alkaline phosphatase measurements. Osteomalacia may still exist even if these tests are normal. When these tests are normal and osteomalacia is still suspected serum 25-hydroxy vitamin $\mathrm{D}$ is usually measured. However, this is expensive and the cheaper parathormone assay should be considered. A low normal calcium and an elevated parathormone indicates secondary hyperparathyroidism and treatment with calcium (800 mg daily) together with vitamin D (400-800 units daily) should be given. See boxes 1 and 2 for summary strategies for the prevention of and treatment of osteoporosis in coeliac disease and IBD.

\subsection{TIMING OF DENSITOMETRY}

The timing of densitometry presents a problem. In women, postmenopausal densitometry will be more sensitive at detecting osteoporosis but the delay will give less scope for achieving a higher bone density with treatment, despite evidence that bisphosphonates may produce some reversal of osteoporosis. ${ }^{44}{ }^{45}$ Conversely, screening at presentation may reveal osteoporosis at a young age when intervention would theoretically have greater potential but for which specific treatments such as bisphosphonates and calcitonin have not been shown to be either effective at preventing fractures (except for those on steroids) or safe.

On balance, one could recommend that all patients have densitometry at diagnosis. This would allow reinforcement of general advice if $\mathrm{BMD}$ is low. However, we can appreciate that the burden on both the clinician and the densitometry service might be counter-productive and deter any screening. A simpler strategy, omitting $\mathrm{BMD}$ at presentation in younger patients and restricting BMD measurement to the older patients who are more likely to benefit, could therefore be more effective in IBD. In any case, patients with IBD at presentation are unlikely to have osteoporosis as a result of their disease. There is more reason for measuring $\mathrm{BMD}$ at diagnosis in patients with coeliac disease because they will already have suffered malabsorption for many years. In women, if the diagnosis is made earlier the BMD should be measured at the menopause. It is debateable whether a single measurement at 
Box 2-Summary strategy for prevention and treatment of osteoporosis in inflammatory bowel disease

GENERAL ADVICE

- Adequate dietary calcium; add calcium tablets if necessary to ensure daily intake of $1500 \mathrm{mg} \star \star \star$

- Exercise $\star \star \star$

- No smoking $\star \star$

- No alcohol excess $\star \star$

- Seek and treat vitamin D deficiency

POSTMENOPAUSAL wOMEN

- Measure BMD at menopause or when first seen

- If osteoporotic $†$ offer

- HRT, preferably by skin patch, or $\star \star \star$

- Bisphosphonate orally, or $\star \star \star$

- Calcitonin $\star \star \star$

MEN >55 YEARS

- Measure BMD in all patients with Crohn's disease and in those with ulcerative colitis who have received systemic steroids

- If osteoporotict, measure serum testosterone and if low, give replacement *

- If testosterone normal or if BMD does not improve on testosterone offer bisphosphonate or calcitonin $\star \star$

ALL IF SYSTEMIC STEROIDS USED

- Give lowest dose for as short as possible

- Concurrently give 800 units vitamin D daily-for example two "calcium and vitamin D" or two Calcichew D3 Forte tablets daily $\star \star$

- Measure BMD and repeat each year in which steroid treatment given

- If T score $<-1.5^{\star}$ offer bisphosphonate (in addition to vitamin D) $\star \star \star$

ALL WITH FRAGILITY FRACTURE

- Measure BMD

- If osteoporotic† offer HRT (if postmenopausal), bisphosphonate or calcitonin $\star \star$

- If already on HRT consider adding bisphosphonate or calcitonin *

DURATION OF DRUG TREATMENT

- For bisphosphonate and calcitonin measure BMD yearly

- If BMD falls $>4 \%$ per year in two successive years change to another drug

- If no fall continue drug for at least three years - possibly long term $\star \star \star$

- Restart drug if, on stopping, yearly BMD falls $>4 \%$

- For HRT check BMD after 10 years and continue HRT if osteoporosis† persists *

†Osteoporosis defined as BMD $>2.5 \mathrm{SD}$ below mean for young adult. ${ }^{\star \star \star}$, ${ }^{\star \star}$ and $\star$ indicate the level of evidence for the recommendation (see text).

the menopause is adequate because there is considerable variation in the rate and duration of rapid perimenopausal bone loss. For this reason it would be sensible to repeat the BMD after perhaps two years in those whose BMD does not suggest osteoporosis. Similarly, in men the BMD should be measured at about 55 years of age if they presented at an earlier age. BMD should be done at any age if there has been a fragility fracture, namely one which is atraumatic or follows a simple fall.

6.3 BONE MINERAL DENSITY TREATMENT THRESHOLD

There is poor agreement on the BMD treatment threshold. Osteoporosis as defined as a $\mathrm{T}$ score below -2.5 would seem the obvious threshold. However, as BMD falls progres- sively with age, this might lead to treatment of most very elderly patients. To ration the treatment some recommend a threshold based on the $\mathrm{Z}$ score below -1 . For those on steroids a $\mathrm{T}$ score below -1.5 has been recommended as a treatment threshold.

6.4 TREATMENT OPTIONS

If osteoporosis is found (i.e., the BMD is more than 2.5 SD below the mean for a young adult) in postmenopausal women, they can be offered treatment with hormone replacement therapy (HRT), a bisphosphonate, or calcitonin. There are no studies of comparability but all these are effective at reducing fracture risk in postmenopausal osteoporosis. The pros and cons will need to be discussed so patients can make an informed choice. None of these treatments has been shown to reduce the fracture rate in patients with coeliac disease or IBD, but there is no reason to suspect that such patients would benefit less than patients with osteoporosis from other causes.

\subsubsection{Hormone replacement therapy}

Hormone replacement therapy has been shown to reduce fracture risk in postmenopausal women in general ${ }^{46}$ and those with osteoporotic fracture in particular, ${ }^{47}$ and to prevent bone loss in patients with IBD. ${ }^{48}$ It is necessary to treat roughly only eight $(95 \%$ confidence interval (CI) 3 to 17) postmenopausal women with osteoporotic fractures for one year to prevent one having a further vertebral fracture during that year. ${ }^{47}$ During HRT the rate of menopausal loss of bone density falls and there may even be a small increase in bone density. Withdrawal of HRT leads to a rise in the rate of bone loss, but only to the same rate as normal postmenopausal bone loss. ${ }^{49}$ This randomised controlled trial suggests that HRT buys time for the skeleton, the benefit being proportional to the duration of treatment. However, in a case controlled study ${ }^{50}$ no substantial reduction in fracture risk was shown after HRT had been discontinued-even after more than 10 years' treatment. Maximal benefit will clearly be achieved by life-long HRT beginning at the menopause, ${ }^{50}$ but this will not be acceptable to many women for a variety of reasons including the return of menstruation and the fear of breast cancer. Tibolone, which may be as effective as standard HRT, can be used to avoid menstruation. The risk of breast cancer may be increased by $15-30 \%$ after 10 years' treatment $^{51}$ or even after only five years. ${ }^{52}$ Although the overall benefit of HRT, especially with regard to cardiovascular disease, may outweigh the risks, the survival benefit diminishes with longer duration of use, particularly for women at low risk of coronary disease, ${ }^{53}$ and there are few data on the effects of such long term use which could amount to 30 years. For this reason the usual initial aim is 10 years' treatment. BMD measurement at the end of this time, or sooner if the patient wishes to stop prematurely, would help in deciding whether or not to continue. It is unlikely that the usual short term use of HRT at the menopause will confer any significant protection against 
osteoporotic fracture. If there is doubt about continuing malabsorption, a skin patch preparation would be appropriate.

\subsubsection{Bisphosphonates}

Bisphosphonates are synthetic analogues of inorganic pyrophosphate that inhibit bone resorption. Cyclical etidronate ${ }^{545}$ and alendronate, ${ }^{44}{ }^{45}$ both given with $500 \mathrm{mg}$ calcium daily, can reduce postmenopausal fractures, although the benefits should not be exaggerated. One study ${ }^{45}$ suggests it is necessary to treat about 14 (95\% CI 10 to 16$)$ and another ${ }^{44}$ about 33 (95\% CI 17 to 1000 ) postmenopausal osteoporotic women with alendronate for three years to prevent one new vertebral fracture ${ }^{44} 45$ and 83 (95\% CI 43 to 1700) patients to prevent one new hip fracture. ${ }^{45}$ These drugs are well tolerated although nausea, diarrhoea and constipation have been reported. They are poorly absorbed and need to be taken on an empty stomach some time before the next meal, and antacids should be avoided. Malabsorption may impair their efficacy. Alendronate may cause oesophagitis and oesophageal ulceration and has to be taken with $200 \mathrm{ml}$ water immediately after getting up in the morning and without lying down for the next half hour.

\subsubsection{Calcitonin}

Calcitonin is a naturally occurring hormone which also inhibits bone resorption. ${ }^{56}$ It is usually given with $500 \mathrm{mg}$ calcium daily. One study $^{57}$ of calcitonin given by nasal spray suggested that treating seven (95\% CI 4 to 38 ) women with postmenopausal osteoporosis for two years prevents one having a new fracture. Confirmation of this impressive result is awaited. It is safe and devoid of any serious or long term side effects and may also reduce osteoporotic bone pain. Unfortunately, the nasal spray is not yet generally available and treatment must be given by intramuscular or subcutaneous injection, thus making it unattractive. Furthermore, calcitonin is much more expensive than bisphosphonates-roughly eight times more expensive than alendronate and sixteen times more expensive than etidronate.

\subsection{DURATION OF TREATMENT}

The optimum duration of treatment with bisphosphonates or calcitonin is not known nor is it known how reliably non-responders can be detected in the short term. Until more information is available it is suggested that BMD is measured yearly while on treatment. If over two successive years there is deterioration in the BMD (e.g., $>4 \%$ per year ${ }^{58}$ ), treatment should be changed to the other drug. If there is no deterioration then treatment should be continued for at least three years, and possibly for as long as osteoporosis persists. Currently, experience of bisphosphonate treatment is confined to five years and it seems to be safe. ${ }^{59}$ If there is deterioration at the yearly BMD measurement after cessation, the treatment should be restarted.
6.6 COMBINATION TREATMENT

No patient on HRT was included in the studies of these drugs and so it is not known whether combined treatment is beneficial. Until such studies have been done, it would seem reasonable to add one of these drugs to HRT or vice versa if an osteoporotic fracture occurs while on single treatment.

\subsection{GUIDELINES IN MEN}

Guidelines are more difficult in men. They certainly seem to have a similar risk of osteoporosis to women in coeliac disease and IBD. Furthermore, there are no conceptual reasons to deny the applicability of BMD measurements in devising a strategy for men as for women. ${ }^{60}$ There are no studies of the effect of bisphosphonates or calcitonin on either $\mathrm{BMD}$ or fracture prevention in men. However, there is no theoretical reason why these treatments would not be as effective in older men (e.g., over 55 years old) as in postmenopausal women, ${ }^{60}$ and so, until those studies have been done it would seen reasonable to consider a bisphosphonate or calcitonin in men over 55 years of age with osteoporosis, especially in those with a fragility fracture. In fact, given the seriousness of fragility fractures drug treatment should be considered at a younger age in both men and women, acknowledging that its effectiveness is unproved. BMD should be measured in all men with Crohn's disease and those men with ulcerative colitis who have received steroids at age 55 years (or later if they present when older) and, if there is osteoporosis, serum testosterone should be measured and testosterone given if low.

\subsection{MANAGING STEROID USE}

\subsubsection{Steroid dose}

All patients requiring systemic steroids should have the lowest dose for as short a time as possible. There seems to be no advantage in terms of preservation of BMD from alternate day regimens. Oral controlled release budesonide should be considered instead of prednisolone for maintenance treatment in appropriate patients. ${ }^{61}$ There have been no studies looking at BMD on budesonide but theoretically it is less likely to cause osteoporosis and other systemic affects. Deflazacort is a newer steroid which also may be associated with a lower risk of osteoporosis ${ }^{62}$ but there are no published studies in IBD.

It is usual to restrict intervention in patients on steroids for those who are likely to receive the equivalent of $7.5 \mathrm{mg}$ or more of prednisolone for more than six months. It is difficult in IBD to predict requirements. That depends on the frequency of relapse and, particularly in Crohn's disease, whether there is likely to be long term treatment. It would therefore seem appropriate to intervene in all patients with IBD embarking on steroids.

\subsubsection{Vitamin D}

Prevention or treatment of steroid induced bone loss by vitamin $\mathrm{D}$ has been the subject of several studies. ${ }^{63-71}$ Four $^{63-66}$ of these nine studies appeared to show benefit. However, it is 
difficult to compare the results and to apply them because the investigators used different vitamin $\mathrm{D}$ preparations for different lengths of time, there were differing steroid dosing regimens, some were not randomised controlled trials, the method of assessment of bone density varied, in some the number of patients was small, and the patients had a variety of different diseases. No reduction in fractures has been demonstrated by any of these studies. Nevertheless, two of the largest randomised controlled trials ${ }^{6566}$ did show a significant reduction in bone loss - one ${ }^{66}$ used vitamin D3 (cholecalciferol) and the other ${ }^{65}$ calcitriol. The use of vitamin D is not without risk $^{72}$ and hypercalcaemia occurred in a quarter of the patients on calcitriol. ${ }^{65}$ On the basis of these two studies we recommend the routine use of vitamin $\mathrm{D}$ in patients with IBD while they receive steroids. Because of the risk of hypercalcaemia with calcitriol we favour vitamin D2 or D3 depending on availability (they are equivalent). In the UK a convenient preparation is "calcium and ergocalciferol" ("calcium and vitamin D"). Two tablets daily provide 800 units of vitamin D (and $200 \mathrm{mg}$ calcium), as recommended by the American College of Rheumatology. ${ }^{43}$ This treatment seems to be safe without monitoring. These tablets are like chalk and have to be chewed or crushed before swallowing. If they are not well tolerated two tablets of Calcichew D3 Forte (Shire, UK) could be used instead. This also provides 800 units of vitamin $\mathrm{D}$ (cholecalciferol) but rather more calcium $(1000 \mathrm{mg})$. Additional dietary calcium would therefore not be advised. Although the above studies of vitamin D were mainly of patients with rheumatology disorders and asthma rather than IBD, we are further encouraged to use this treatment in IBD because one study ${ }^{73}$ of 1000 units daily of vitamin D3 in patients with Crohn's disease (of whom one third received steroids) prevented bone loss. Furthermore, another study ${ }^{74}$ of 700 units daily of vitamin D3 for three years in healthy people over 65 years caused a significant reduction in non-vertebral fractures (vertebral fractures were not assessed). This suggests that roughly 14 (95\% CI 8 to 34$)$ people over 65 years of age need to be treated for three years to prevent one non-vertebral fracture. Nevertheless, this is indirect evidence and a controlled study of vitamin D in patients with IBD receiving steroids would be appropriate.

\subsubsection{Bisphosphonates}

Bisphosphonates have also been shown to be effective at reducing steroid induced bone loss. There are five studies, ${ }^{75-79}$ all of which were for one year and showed benefit. One ${ }^{76}$ was not a randomised controlled trial. Two ${ }^{77}{ }^{79}$ were on patients embarking on steroids, and three $e^{75} 7678$ were on patients on long term steroids, one of which comprised patients with established osteoporosis. ${ }^{78}$ One study used the bisphosphonate APD ((3-amino-1-hydroxypropylidene)-1, 1-bisphosphonate $)^{75}$ and the other four used cyclical etidronate. The largest study ${ }^{79}$ (141 patients who had recently started steroids), as well as showing prevention of spinal and hip bone loss, also demonstrated a reduction in vertebral fractures in the subgroup of postmenopausal women. This study suggests that approximately five post-menopausal women starting on steroids need to be treated with a bisphosphonate for one year to prevent one having a vertebral fracture. Thus, a bisphosphonate could be recommended for those on steroids if vitamin $\mathrm{D}$ is either ineffective or cannot be tolerated. The use of these drugs in combination for patients with severe bone disease has been advised. ${ }^{80}$ Although this is logical, the combination has not been studied.

\subsubsection{Bone mineral density threshold for treatment}

There is no direct evidence on which to base a threshold of BMD for giving a bisphosphonate. The UK Consensus Group ${ }^{81}$ recommends treatment for a $\mathrm{T}$ score below -1.5 .

\subsubsection{Summary for patients on steroids}

In summary, for those on steroids, we recommend 800 units of vitamin D daily for the duration of steroid therapy. BMD should be measured, and repeated every year in which steroids are given if the $\mathrm{T}$ score is $<0$. If the $\mathrm{T}$ score is $>0$ the BMD should be re-measured every three to five years. ${ }^{81}$ If the $\mathrm{T}$ score is less than -1.5 we would offer a bisphosphonate, usually in addition to vitamin D.

\subsection{Conclusion}

Although these suggested strategies are based on published evidence as far as possible, they are of necessity arbitrary to some extent because there are many gaps in our knowledge. An attempt has been made to indicate the areas where therapeutic research would be most useful. Clearly, alternative strategies might be just as valid, and any strategy will require modification in the light of new knowledge. In the meantime it is hoped that these guidelines will form a basis for rational management of two common gastrointestinal disorders.

\subsection{Search strategy}

Medline was searched back to 1990 using the subjects osteoporosis and bone density combined with inflammatory bowel disease, Crohn's disease, ulcerative colitis, and coeliac disease. All relevant papers were obtained and further papers obtained by scrutiny of the reference lists.

\subsection{Levels of evidence for recommendations}

The various recommendations in the summary strategies are graded ${ }^{\star \star \star}, \star \star$ and ${ }^{\star}$ according to the level of evidence: ${ }^{\star \star \star}$ Evidence based upon well designed randomised controlled trials ${ }^{\star \star}$ Evidence from:

(1) prospective non-randomised controlled trials or;

(2) good observation studies or;

(3) retrospective and cross sectional studies or; 
(4) extrapolated from $\star \star \star$.

*Evidence from:

(1) expert committee reports or opinions and/or clinical experience of respected authorities or;

(2) extrapolation from ${ }^{\star \star}$.

\subsection{Process of guideline formulation}

The guidelines were first drafted by Dr Eleanor $M$ Scott (Registrar in Endocrinology at St James's University Hospital, Leeds, UK) and Dr Brian B Scott (Consultant Gastroenterologist at Lincoln County Hospital, UK). These were then sent to Dr Ian Gaywood (Consultant Rheumatologist at Lincoln County Hospital) for comments and suggestions. The guidelines were then sent to the European fournal of Gastroenterology and Hepatology where they were modified considerably after detailed review by four experts including Dr Juliet Compston (Cambridge, UK) and Professor Richard Eastell (Sheffield, UK). They were then published (Scott EM, Scott BB. A strategy for osteoporosis in gastroenterology. Eur 7 Gastroenterol Hepatol 1998;10:689-98). The guidelines were then redrafted in a form suitable for the British Society of Gastroenterology and reviewed by all members of the Clinical Services \& Standards Committee of the British Society of Gastroenterology. The guidelines were then again redrafted taking into account the very many comments.

\subsection{References}

1 Melton LJ, Chrischilles EA, Cooper C, et al. How many women have osteoporosis? f Bone Miner Res 1992;9:100510.

2 Department of Health. Report of the advisory group on osteoporosis. London: HMSO, 1994.

3 WHO Study Group on Assessment of Fracture Risk and its Application to Screening for Post Menopausal Osteoporosis. Assessment of fracture risk and its application to screening for post menopausal osteoporosis: report of a WHO study group. for post menopausal osteoporosis: report of a WHO study

4 Melton LJ, Atkinson EJ, O'Fallon WM, et al. Long-term fracture risk prediction with bone mineral measurements made at various skeletal sites? $f$ Bone Miner Res made at various ske

5 Cummings SR, Black DM, Nevitt MC, et al. Bone density at various sites for prediction of hip fractures. Lancet 1993;341:72-5

6 Porter RW, Miller CG, Grainger D, et al. Prediction of hip fracture in elderly women: a prospective study. $B M F 1990$ 301:638-41.

7 Lotz JC, Gerhart TN, Hayes WC. Mechanical properties of trabecular bone from the proximal femur: a quantitative CT study. 7 Comput Assist Tomogr 1990;14:107-14.

8 Marshall D, Johnell O, Wedel H. Meta-analysis of how well measures of bone mineral density predict occurrence of osteoporotic fractures. BMF 1996;312:1254-9.

9 Anonymous. Screening for osteoporosis to prevent fractures: bulletin on the effectiveness of health services intervention for decision makers. Vol 1. London School of Public Health, Sion makers. sity of York, Research Unit of the Royal College of sity of York, Research Unit of the Roy

10 Sheldon TA, Raffle A, Watt I. Department of Health shoots itself in the hip. BMF 1996;312:296-8.

11 Compston JE, Cooper C, Kanis JA. Bone densitometry in clinical practice. $B M F$ 1995;310:1507-10

12 McCloskey EV, Murray SA, Miller C, et al. Broadband ultrasound attenuation in the os calcis: relationship to bone mineral at other skeletal sites. Clin Sci 1990;78:227-33. 13 McCloskey EV, Murray SA, Charlesworth D, et al.
Assessment of broadband ultrasound attenuation in the os calcis in vitro. Clin Sci 1990;78:221-5.

14 Caraceni MP, Molteni N, Bardella MT, et al. Bone and mineral metabolism in adult celiac disease. Am $\mathcal{F}$ Gastroentero 1988;83:274-7.

15 Molteni N, Caraceni MP, Bardella MT, et al. Bone mineral density in adult celiac patients and the effect of gluten-free diet from childhood. Am ₹ Gastroenterol 1990;85:51-3.

16 Bode S, Hassager C, Gudmand-Hoyer E, et al. Body composition and calcium metabolism in adult treated coeliac disease. Gut 1991;32:1342-5.
17 Mazure R, Vasquez H, Gonzalez D, et al. Bone mineral affection in asymptomatic adult patients with celiac affection in asymptomatic adult patient
disease. Am $\mathcal{F}$ Gastroenterol 1994;89:2130-4.

18 Valdimarsson T, Toss G, Ross I, et al. Bone mineral density in coeliac disease. Scand F Gastroenterol 1994;29:457-61.

19 McFarlane XA, Bhalla AK, Reeves DE, et al. Osteoporosis in treated adult coeliac disease. Gut 1995;36:710-14.

20 Walters JRF, Banks LM, Butcher GP, et al. Detection of low bone mineral density by dual energy absorptiometry in unsuspected suboptimally treated coeliac disease. Gut 1995;37:220-4

21 Pistorius LR, Sweiden WH, Purdie DW, et al. Coeliac disease and bone mineral density in adult female patients. Gut 1995;37:639-42

22 Corazza GR, Sario AD, Cecchetti L, et al. Bone mass and metabolism in patients with celiac disease. Gastroenterology 1995;109:122-8

23 Valdimarsson T, Lofman O, Toss G, et al. Reversal of osteopenia with diet in adult coeliac disease. Gut 1996;38:322-

4 Mora S, Weber G, Barera G, et al. Effect of gluten-free diet on bone mineral content in growing patients with celiac disease. Am 7 Clin Nutr 1993;57:224-8.

$25 \mathrm{McF}$ arlane XA, Dixey J, Dumfrey J, et al. Increased risk of bone fractures in coeliac disease [abstract]. Gastroenterology 1996;110:A821

26 Walters JRF. Bone mineral density in coeliac disease. Gut 1994;35:150-1.

27 Farthing MJ, Rees LJ, Edwards CRW, et al. Male gonadal function in coeliac disease. 2. Sex hormones. Gut 1983;24: $127-35$.

28 Finkelstein JS, Klibanski A, Neer RM, et al. Osteoporosis in men with idiopathic hypogonadotropic hypogonadism. Ann Intern Med 1987;106:354-61

29 Compston JE, Judd D, Crawley EO, et al. Osteoporosis in patients with inflammatory bowel disease. Gut 1987;28. 410-15

30 Motley RJ, Crawley EO, Evans C, et al. Increased rate of spinal trabecular bone loss in patients with inflammatory bowel disease. Gut 1988;29:1332-6.

31 Clements D, Motley RJ, Evans WD, et al. Longitudinal study of cortical bone loss in patients with inflammatory bowel disease. Scand f Gastroenterol 1992;27:1055-60.

32 Silvennoinen JA, Karttunen TJ, Niemela SE, et al. A controlled study of bone mineral density with inflammatory bowel disease. Gut 1995;37:71-6.

33 Bischoff SC, Herrman A, Evers J, et al. Bone density and bone metabolism in inflammatory bowel disorders (IBD). A clinical study in

34 Lisciandrano D, Ranzi T, Ulivieri FM, et al. Bone mineral density in patients with ulcerative colitis [abstract]. Gastroenterology 1996;110:A951.

35 Jahnsen J, Falch JA, Aadland E, et al. Bone mineral density is reduced in patients with Crohn's disease but not in patients with ulcerative colitis: a population based study. Gut 1997;40:313-19.

36 Bjarnason I, Macpherson A, MacKintosh C, et al. Reduced bone density in patients with inflammatory bowel disease. Gut 1997;40:228-33.

37 Farthing MJG, Dawson AM. Impaired semen quality in Crohn's disease - drugs, ill health or undernutrition? Scand $\mathcal{F}$ Gastroenterol 1983;18:57-60.

38 Schaison G, Durand F, Mowszowicz I. Effect of glucocorticoids on plasma testosterone in men. Acta Endocrinol (Copenh) 1978;89:126-31

39 MacAdams MR, White RH, Chipps BE. Reduction in serum testosterone levels during chronic glucocorticoid therapy. Ann Intern Med 1968;104:648-51.

40 Manolagas SC, Jilka RL. Bone marrow, cytokines, and bone remodelling - emerging insights into the pathophysiology of osteoporosis. N Engl f Med 1995;332:305-11.

41 Tragone A, Mercuriali B, Vignola ML, et al. Bone mineral density and serum interleukin-6 (IL-6) concentration in patients with Crohn's disease [abstract]. Gastroenterology

42 Lukert BP, Raisz LG. Glucocorticoid-induced osteoporosis: pathogenesis and management. Ann Intern Med 1990;112: 352-64.

43 American College of Rheumatology Task Force on Osteoporosis Guidelines. Recommendations for the prevention and treatment of glucocorticoid-induced osteoporosis. Arthritis Rheum 1996;39:1791-801.

44 Liberman UA, Weiss SR, Broll J, et al. The effect of oral alendronate on bone mineral density and the incidence of fractures in postmenopausal osteoporosis. $N \mathrm{Engl} \mathrm{f} \mathrm{Med}$ 1995;333:1437-43.

45 Black DM, Cummings SR, Karpf DB, et al. Randomised trial of effect of alendronate on risk of fracture in women with existing vertebral fractures. Lancet 1996;348:1535-41.

46 Kiel DP, Felson DT, Anderson JJ, et al. Hip fracture and the use of estrogens in postmenopausal women - The Framingham study. N Engl f Med 1987;317:1169-74.

47 Lufkin EG, Wahner HW, O'Fallon WM, et al. Treatment of postmenopausal osteoporosis with transdermal estrogen. Ann Intern Med 1992;117:1-9.

48 Clements D, Compston JE, Evans WD, et al. Hormone replacement therapy prevents bone loss in patients with inflammatory bowel disease. Gut 1993;34:1543-60.

49 Christiansen C, Christiansen MS, Transbol I. Bone mass in postmenopausal women after withdrawal of oestrogen/ gestagen therapy. Lancet 1981;i:459-61. 
50 Cauley JA, Seeley DG, Ensrud K, et al. Estrogen replacement therapy and fractures in older women. Ann replacement therapy and fract

51 Steinberg KK, Smith SJ, Thacker SB, et al. Breast cancer risk and duration of estrogen use: the role of study design in meta-analysis. Epidemiology 1994;5:415-21.

52 Colditz GA, Hankinson SE, Hunter DJ, et al. The use of estrogens and progestins and the risk of breast cancer in postmenopausal women. N Engl F Med 1995;332:1589-93.

53 Grodstein F, Stampfer MJ, Colditz GA, et al. Postmenopausal hormone therapy and mortality. $N$ Engl $f \mathrm{Med}$ 1997;336:1769-75.

54 Storm T, Thomsborg G, Steinche T, et al. Effect of intermittent cyclical etidronate therapy on bone mass and fracture rate in women with postmenopausal osteoporosis. N Engl f Med 1990;322:1265-71.

55 Watts NB, Harris ST, Genant HK, et al. Intermittent cyclical etidronate treatment of postmenopausal osteoporosis. cal etidronate treatment of post

56 Reginster JY. Calcitonin for prevention and treatment of osteoporosis. Am f Med 1993;95:44-75.

57 Overgaard K, Hansen MA, Jensen SB, et al. Effect of salcatonin given intranasally on bone mass and fracture rates in established osteoporosis: a dose response study. $B M f$ 1992;305:556-61.

58 Eastell R. Management of glucocorticoid-induced osteoporosis. F Intern Med 1995;237:439-47.

59 Storm T, Kollerup G, Thomsborg G, et al. Five years of clinical experience with intermittent cyclical etidronate for postmenopausal osteoporosis. F Rheumatol 1996;23:15604.

60 Orwoll ES, Klein RF. Osteoporosis in men. Endocr Rev 1995;16:87-116.

61 Greenberg GR, Feagan BC, Martin F, et al. Oral budesonide as maintenance treatment for Crohn's disease: A placebocontrolled, dose-ranging study. Gastroenterology 1996;110: 45-51.

62 Messina OD, Barreira JC, Zanchetta JR, et al. Effect of low doses of deflazacort vs prednisolone on bone mineral con-
tent in premenopausal arthritis. F Rheumatol 1992;19: tent in $1520-6$.

63 Hahn TJ, Halstead LR, Teitelbaum SL, et al. Altered mineral metabolism in glucocorticoid-induced osteopenia: effect of 25-hydroxyvitamin D administration. $\mathcal{F}$ Clin Inves 1979;64:655-65.

64 DiMunno O, Boghe F, Favini P, et al. Prevention of glucocorticoid osteopenia: effect of oral 25-hydroxyvitamin $\mathrm{D}$ and calcium. Clin Rheumatol 1989;8:202-7.

65 Sambrook P, Birmingham J, Kelly P, et al. Prevention of corticosteroid osteoporosis - a comparison of calcium, cal-
citriol and calcitonin. N Engl f Med 1993;328:1747-52.

66 Buckley LM, Leib ES, Cartularo KS, et al. Calcium and vitamin D3 supplementation prevents bone loss in the spine secondary to low-dose corticosteroids in patients with rheumatoid arthritis. Ann Intern Med 1996;125:961-
67 Rickers H, Deding A, Christiansen C, et al. Corticosteroidinduced osteopenia and vitamin D metabolism: effect of vitamin D2, calcium phosphate and sodium fluoride administration. Clin Endocrinol 1982;16:409-15.

68 Braun JJ, Birkenhager-Frenkel DH, Rietveld JR, et al. Influence of $1 \alpha-(\mathrm{OH}) \mathrm{D} 3$ administration of bone and bone mineral metabolism in patients on chronic glucocorticoid treatment: a double blind controlled study. Clin Endocrinol 1983;19:265-73.

69 Dykman TR, Haralson KM, Gluck OS, et al. Effect of oral 1,25-dihydroxyvitamin D and calcium on glucocorticoidinduced osteopenia in patients with rheumatic diseases. Arthritis Rheum 1984;27:1336-43.

70 Bijlsma JWJ, Raymakers JA, Mosch C, et al. Effects of oral calcium and vitamin D on glucocorticoid osteopenia. Clin Exp Rheumatol 1988;6:113-19.

71 Adachi JD, Bensen WG, Bianchi F, et al. Vitamin D and calcium in the prevention of corticosteroid-induced osteoporosis: a 3 year follow-up. F Rheumatol 1996;23:9951000.

72 Marriott BM. Vitamin D supplementation: a word of caution. Ann Intern Med 1997;127:231-3.

73 Vogelsang H, Ferenci P, Resch H, et al. Prevention of bone mineral loss in patients with Crohn's disease by long-term oral vitamin D supplementation. Eur 7 Gastroenterol Hepatol 1995; 7:609-14.

74 Dawson-Hughes B, Harris S, Krall EA, et al. Effect of calcium and vitamin $\mathrm{D}$ supplementation on bone density in men and women 65 years of age or older. $N$ Engl $\mathcal{F}$ Med 1997;337:670-6

75 Reid IR, King AR, Alexander CJ, et al. Prevention of steroid induced osteoporosis with (3-amino-1-hydroxypropylidene)-1,1-bisphosphonate (APD). Lancet 1988;i: 143-6.

76 Adachi JD, Cranney A, Goldsmith CL, et al. Intermittent cyclic therapy with etidronate in the prevention of corticosteroid-induced bone loss. F Rheumatol 1994;21: $1922-6$

77 Mulder H, Struys A. Intermittent cyclical etidronate in the prevention of corticosteroid-induced bone loss. Br f Rheumatol 1994;33:348-50.

78 Struys A, Snelder AA, Mulder H. Cyclical etidronate reverses bone loss of the spine and proximal femur in patients with established corticosteroid-induced osteoporosis. Am f Med 1995;99:235-42.

79 Adachi JD, Bensen WG, Brown J, et al. Intermittent etidronate therapy to prevent corticosteroid-induced osteoporosis. N Engl f Med 1997;337:382-7.

80 Reid IR. Preventing glucocorticoid-induced osteoporosis. $N$ Engl f Med 1997;337:420-1.

81 Eastell R, Reid DM, Compston, J, et al. A UK consensus group of management of cortico-induced osteoporosis: an update. F Intern Med 1998;244:271-92. 